\title{
Continuous flow copper laser ablation synthesis of copper (I and II) oxide nanoparticles in water
}

Ahmed Hussein Mohammed Al-antakia,b, Xuan Luo ${ }^{a, c}$, XiaoFei Duan ${ }^{d}$, Robert N.

Lamb $^{d}$, Wayne D. Hutchison ${ }^{e}$, Warren Lawrancef, Colin L. Raston ${ }^{a^{*}}$

a Flinders Institute for Nanoscale Science and Technology, College of Science and Engineering, Flinders University, Adelaide, SA 5042, Australia.

b Department of Chemistry, Faculty of Sciences, Kufa University, Kufa, Najaf, Iraq.

c Centre for Marine Bioproducts Development, College of Medicine and Public Health, Flinders University, Adelaide, SA 5042, Australia.

d Trace Analysis for Chemical, Earth and Environmental Sciences (TrACEES), University of Melbourne, Victoria 3010, Australia.

e School of Science, University of New South Wales, ADFA campus, Canberra BC, ACT 2610, Australia.

$f$ College of Science and Engineering, Flinders University, Adelaide, SA 5042, Australia.

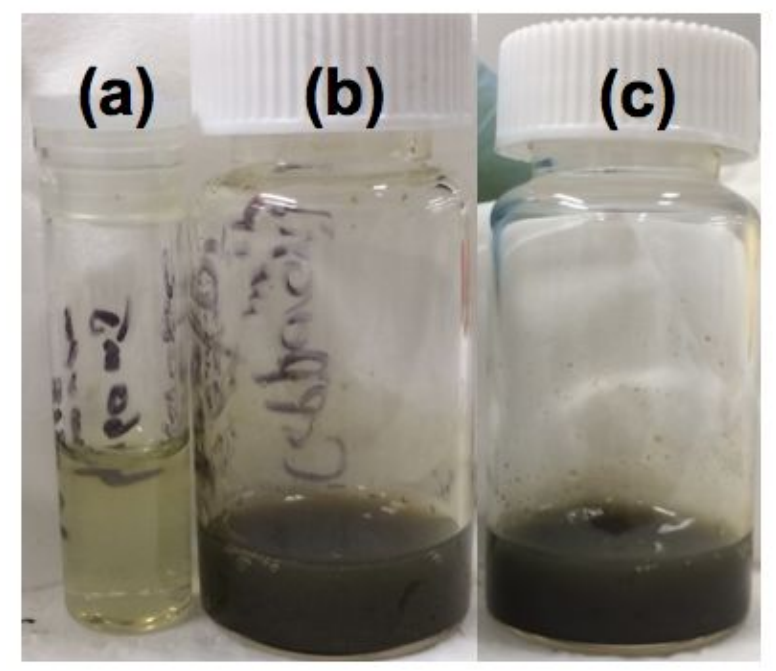

Figure S1. Confined mode synthesis in a VFD for $15 \mathrm{mins}$, for $1 \mathrm{~mL}$ of water, tilt angle $45^{\circ}$, and rotational speed $7.5 \mathrm{k} \mathrm{rpm}$, coupled with a $1064 \mathrm{~nm}$ pulse laser operating at (a) $450 \mathrm{~mJ}$, (b) $550 \mathrm{~mJ}$, and (c) $600 \mathrm{~mJ}$. 


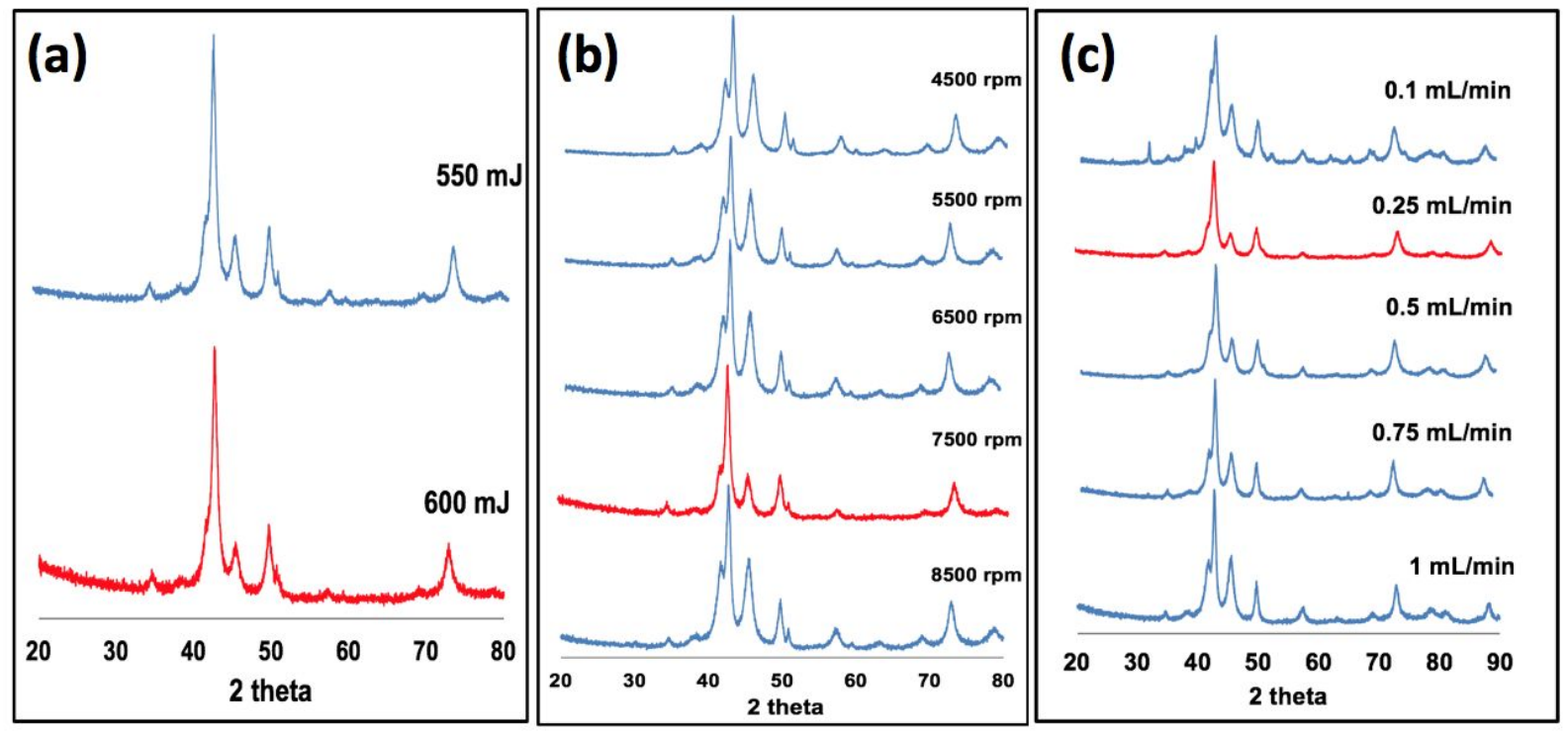

Figure S2. X-ray diffraction data (Co source, $\lambda=1.7889 \mathrm{~A}^{\circ}$ ): (a) Different laser power $(550 \mathrm{~mJ}, 600 \mathrm{~mJ})$ for 15 mins of VFD processing in the confined mode, for $1 \mathrm{~mL}$ of water, and rotation speed $7.5 \mathrm{k} \mathrm{rpm}$. (b) Confined mode for $15 \mathrm{mins}, 1 \mathrm{~mL}$ of water and laser power at $600 \mathrm{~mJ}$ with different rotation speeds of the glass tube in a VFD (4.5, $5.5,6.5,7.5$ and $8.5 \mathrm{k} \mathrm{rpm})$. (c) Continuous flow processing at different flow rates $(0.1$, $0.25,0.5,0.75$ and $1 \mathrm{~mL} / \mathrm{min}$ ), rotational speed $7.5 \mathrm{k} \mathrm{rpm}$, laser power $600 \mathrm{~mJ}$, to collect $10 \mathrm{~mL}$ of the liquid. All experiments were at a tilt angle of $45^{\circ}$.

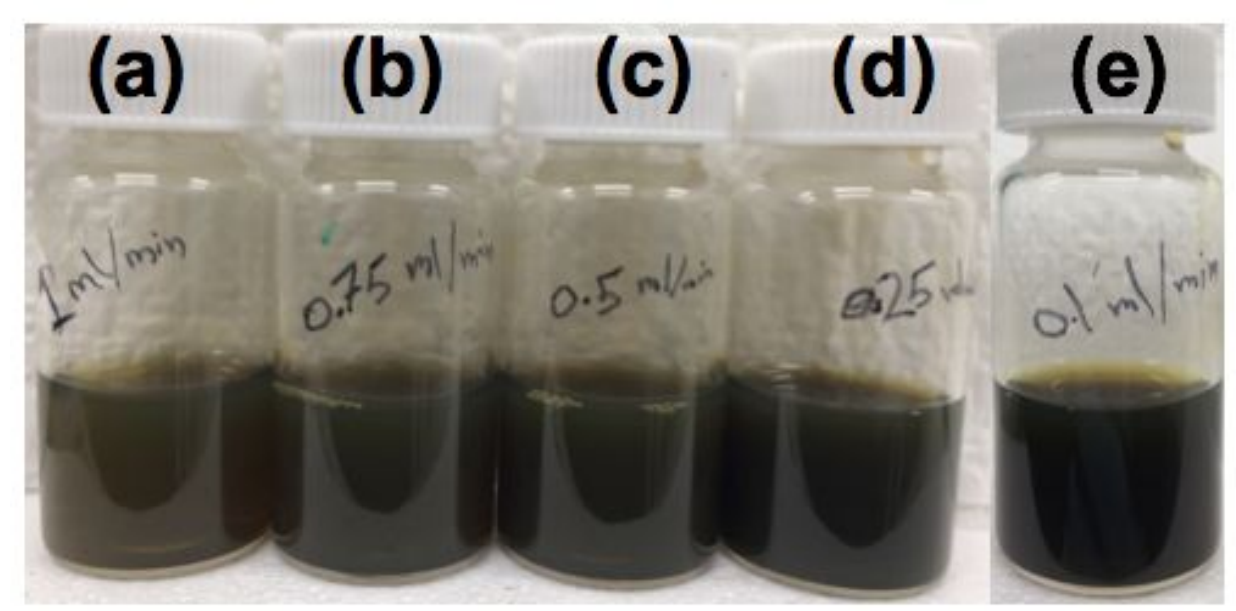

Figure S3. Photographs of solutions from $10 \mathrm{~mL}$ of processed liquid generated for the experiments in Fig.S2c at flow rates of (a) $1 \mathrm{~mL} / \mathrm{min}$, (b) $0.75 \mathrm{~mL} / \mathrm{min}$. (c) $0.5 \mathrm{~mL} / \mathrm{min}$, (d) $0.25 \mathrm{~mL} / \mathrm{min}$, (e) $0.1 \mathrm{~mL} / \mathrm{min}$. 


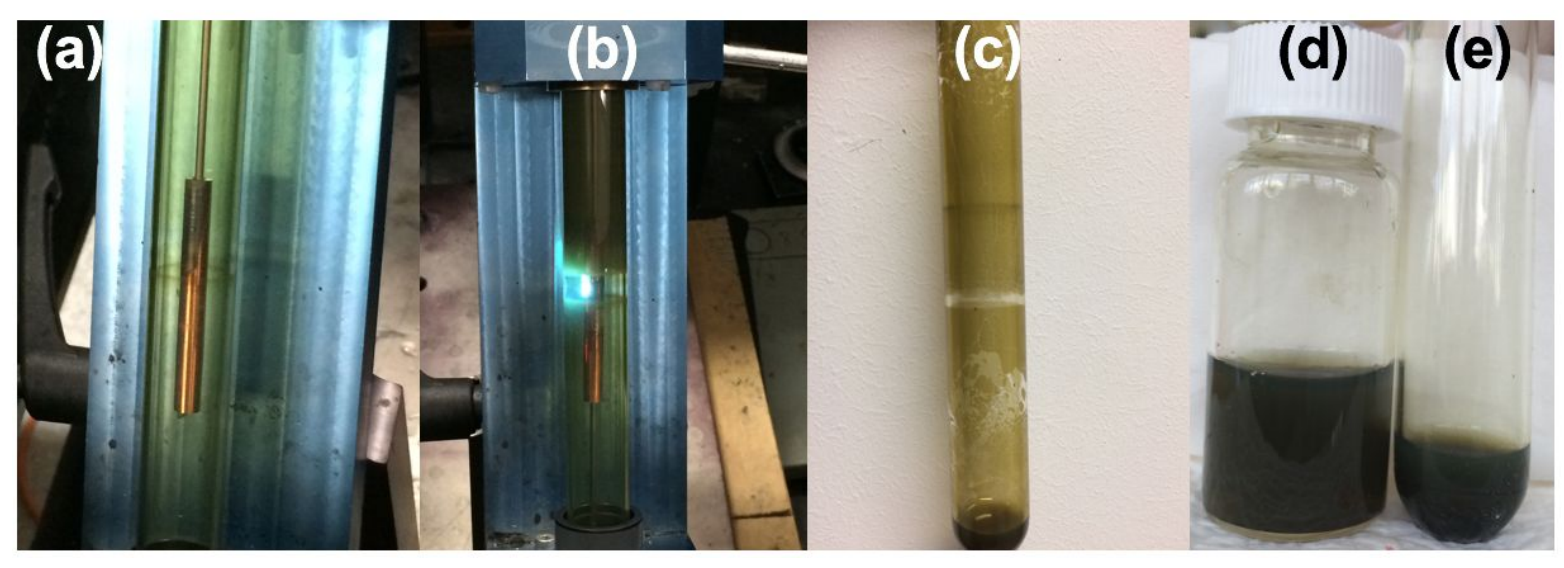

Figure S4. Photographs showing (a) the copper rod positioned inside the glass tube in a VFD rotating at $7.5 \mathrm{k} \mathrm{rpm}$, (b) $600 \mathrm{~mJ}$ pulsed laser irradiation (1064 nm wavelength) of the copper rod for (a) operating in the confined mode after 15 min, (c) the VFD tube after $2 \mathrm{~h}$ of continuous flow with the tube rotating at $7.5 \mathrm{k} \mathrm{rpm}$ in the VFD housing the copper rod irradiated at $600 \mathrm{~mJ}$, as for (a), (d) the solution exited from the VFD for experiments in (c), and (e) the solution left in the VFD tube after $2 \mathrm{~h}$ of the processing. All experiments were at a tilt angle of $45^{\circ}$.

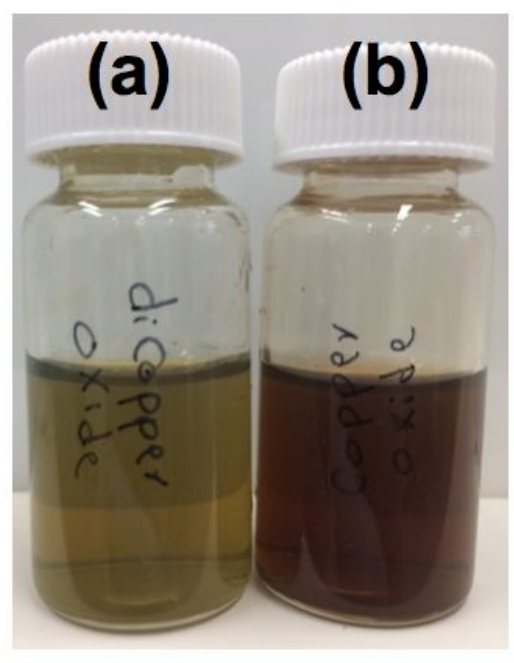

Figure S5. (a) Dispersion of $\mathrm{Cu}_{2} \mathrm{ONPs}$ in water produced at $600 \mathrm{~mJ}$ pulsed laser power, $7.5 \mathrm{k} \mathrm{rpm}$ rotational speed and at $0.25 \mathrm{~mL} / \mathrm{min}$, tilt angle $45^{\circ}$. (b) Dispersion of CuONPs after the solution from (a) was heated in oven at $50^{\circ} \mathrm{C}$ for $10 \mathrm{~h}$. 


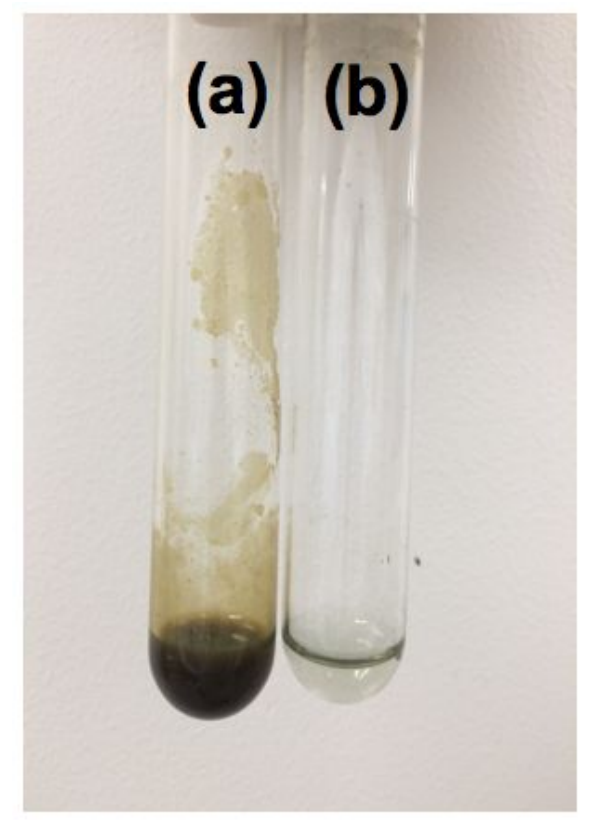

Figure S6. Solutions after 15 min confined mode experiments, rotational speed $7.5 \mathrm{k}$ rpm, pulsed laser $600 \mathrm{~mJ}$ and tilt angle $45^{\circ}$ under different atmospheres: (a) air and (b) nitrogen gas.
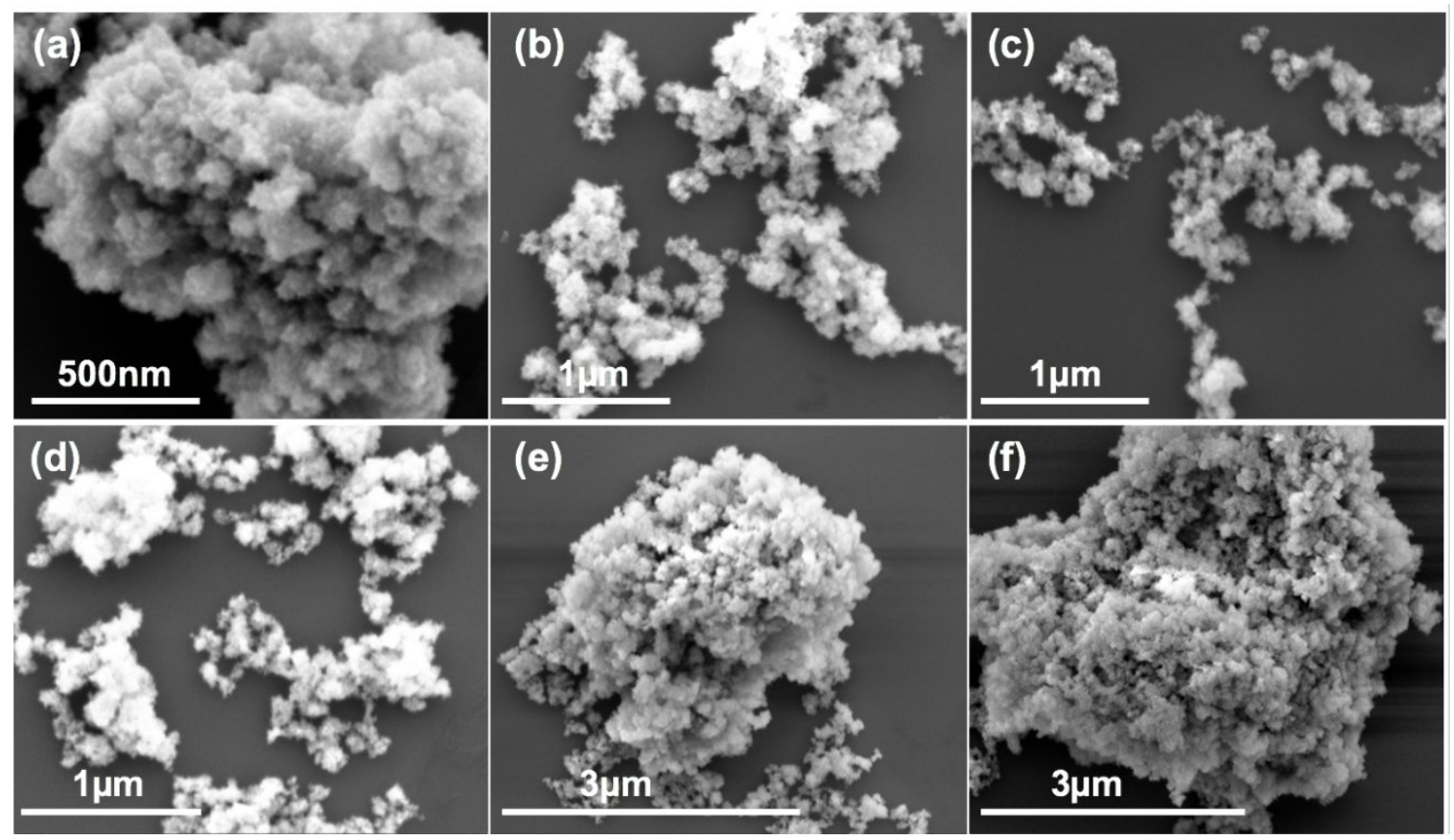

Figure S7. SEM images prepared via drop cast of material formed and spin coating, using a VFD under continuous flow of water at $0.25 \mathrm{~mL} / \mathrm{min}$, with the glass tube at $45^{\circ}$ tilt angle and rotating at $7.5 \mathrm{k} \mathrm{rpm}$, using a $1064 \mathrm{~nm}$ pulsed laser operating at $600 \mathrm{~mJ}$, irradiating a pure copper target, (a-c) as prepared $\mathrm{Cu}_{2}$ ONPs and (d-f) CuONPs after heating the as prepared solutions at $50^{\circ} \mathrm{C}$ for $10 \mathrm{~h}$. 


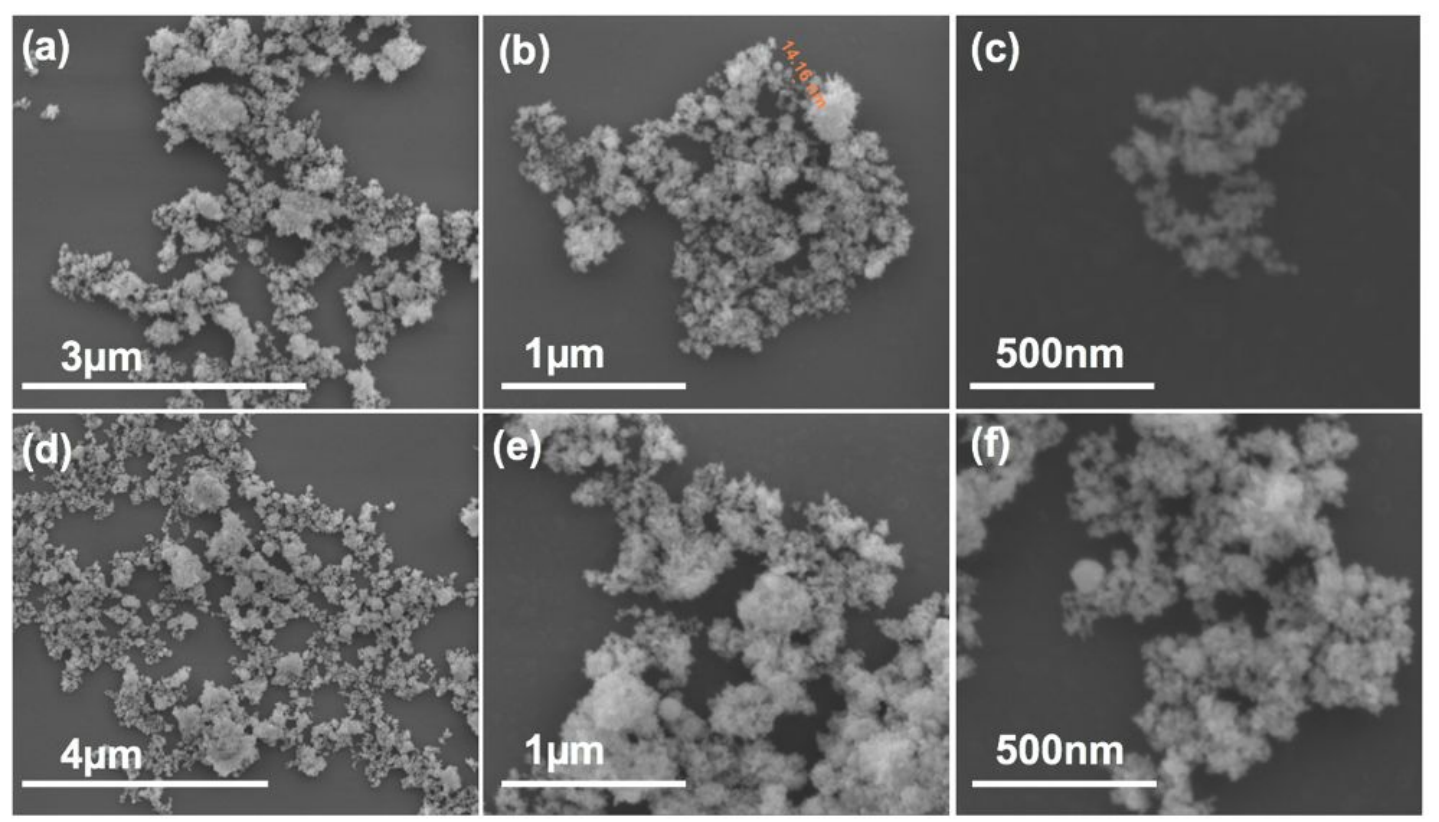

\section{(g)}

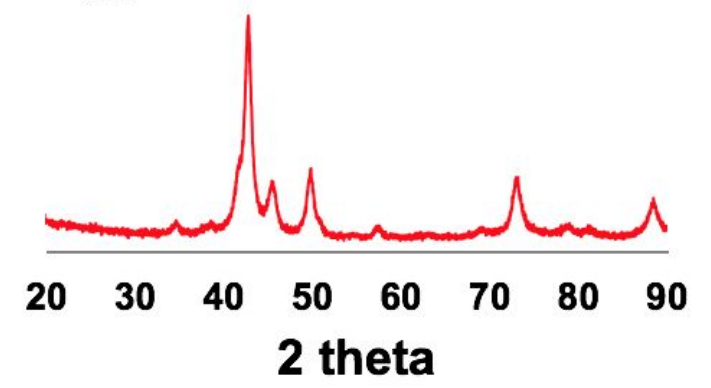

(h)

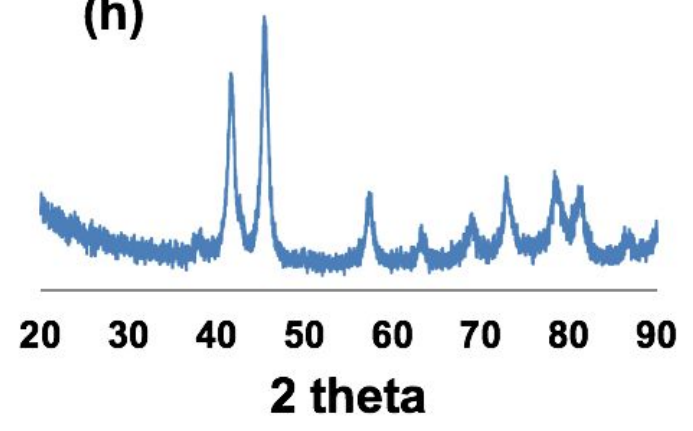

Figure S8. SEM images of material after drop casting solutions left in the tube following the experiments in Fig. S7: (a-c) $\mathrm{Cu}_{2} \mathrm{ONPs}$ (d-f) CuONPs, (g) XRD for dicopper oxide in the tube, and (h) XRD for copper oxide after leaved $\mathrm{Cu}_{2} \mathrm{ONPs}$ collected from the tube as solution in oven at $50^{\circ} \mathrm{C}$ for $10 \mathrm{~h}$. 

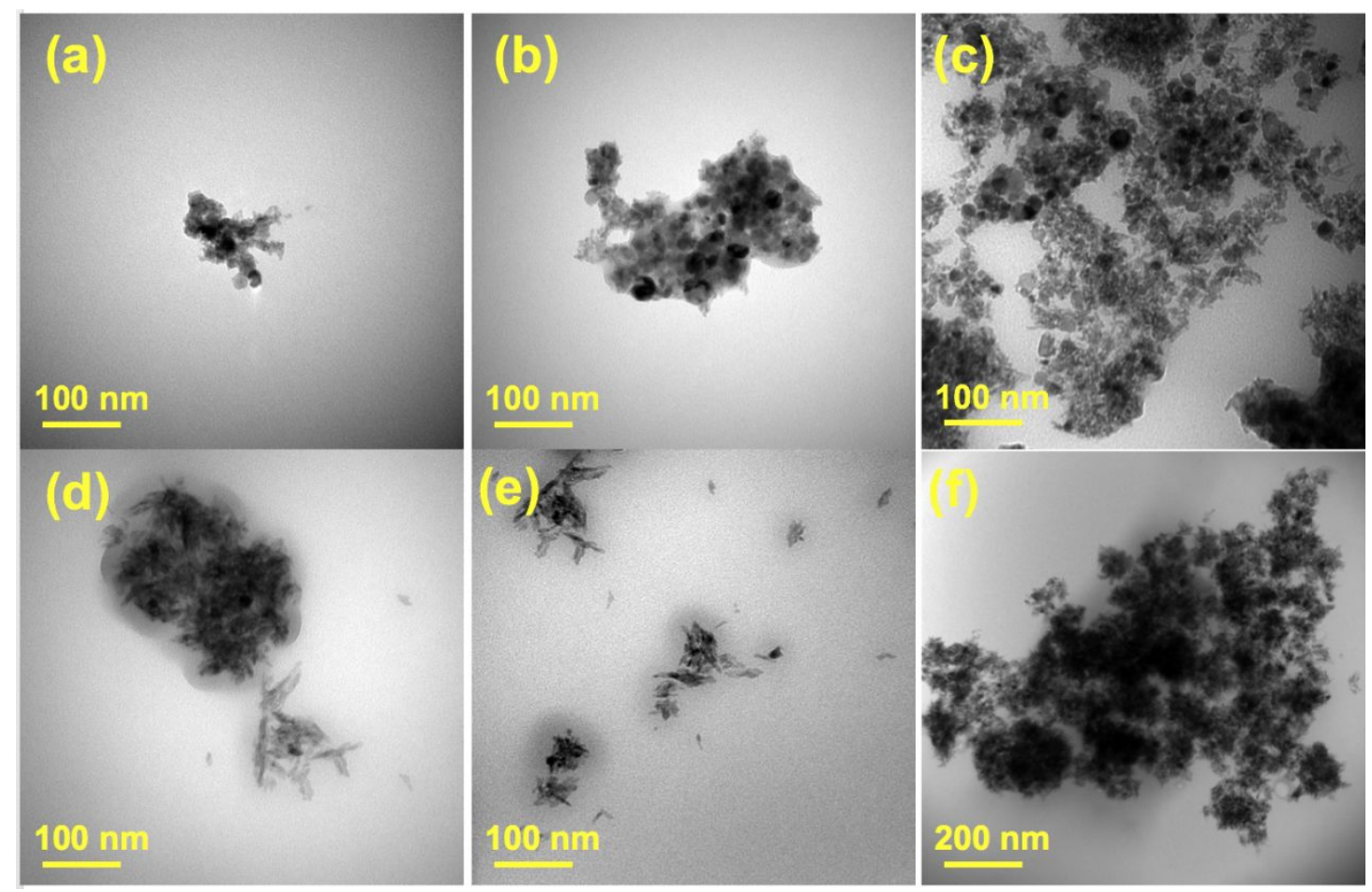

Figure S9. TEM images of material formed using a VFD under continuous flow of water at $0.25 \mathrm{~mL} / \mathrm{min}, 45^{\circ}$ tilt angle, using a $1064 \mathrm{~nm}$ pulsed laser operating at $600 \mathrm{~mJ}$ irradiating a copper target, (a-c) as prepared $\mathrm{Cu}_{2} \mathrm{ONPs}$ and (d-f) CuONPs after heating as prepared solutions at $50^{\circ} \mathrm{C}$ for $10 \mathrm{~h}$.
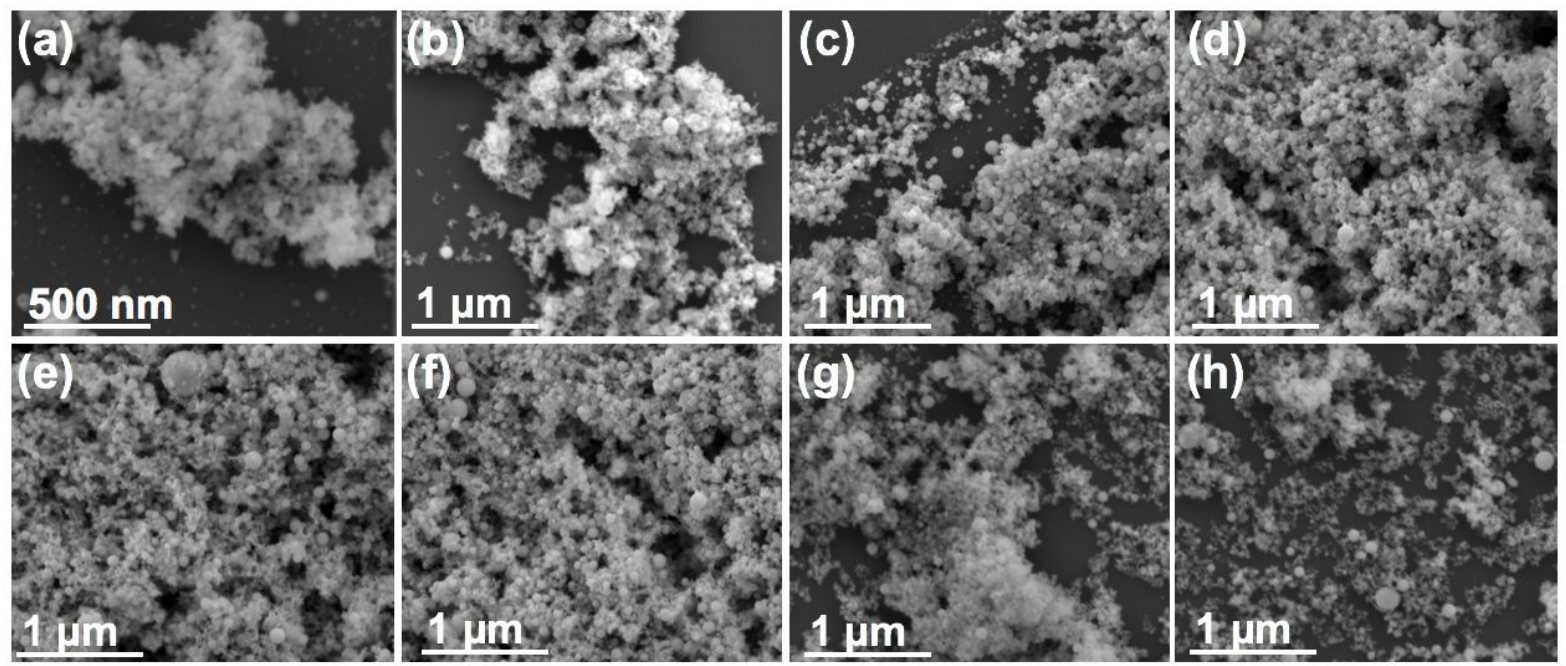

Figure S10. (a-h) SEM images of material deposited by drop casting material formed using a VFD in the confined mode for $1 \mathrm{~mL}$ of water for $15 \mathrm{~min}$, with the glass tube at $45^{\circ}$ tilt angle and rotating at $4 \mathrm{k} \mathrm{rpm}$, using a $1064 \mathrm{~nm}$ pulsed laser operating at 600 $\mathrm{mJ}$ irradiating a copper target, 